2010-03

\title{
A five-gene signature as a potential predictor of metastasis and survival in colorectal cancer.
}

Hao, J-M

http://hdl.handle.net/10026.1/10314

10.1002/path.2668

J Pathol

All content in PEARL is protected by copyright law. Author manuscripts are made available in accordance with publisher policies. Please cite only the published version using the details provided on the item record or document. In the absence of an open licence (e.g. Creative Commons), permissions for further reuse of content should be sought from the publisher or author. 


\title{
Original Paper
}

\section{A five-gene signature as a potential predictor of metastasis and survival in colorectal cancer}

\author{
Jun-Mei Hao, ${ }^{-3 \dagger}$ Juan-Zhi Chen, ${ }^{2,3 \dagger}$ Hong-Mei Sui,' Xue-Qing Si-Ma,' Guang-Qiu Li,' Chao Liu,' Ji-Liang Li, ${ }^{4,5}$ \\ Yan-Qing Ding ${ }^{1-3 *}$ and Jian-Ming Lil-3* \\ 'Department of Pathology, School of Basic Medical Sciences, Southern Medical University, Guangzhou 5 I05 I5, People's Republic of China \\ ${ }^{2}$ Department of Pathology, Nanfang Hospital, Southern Medical University, Guangzhou 51 0515, People's Republic of China \\ ${ }^{3}$ Guangdong Provincial Key Laboratory of Molecular Tumour Pathology, Guangzhou 5 105 15, People's Republic of China \\ ${ }^{4}$ School of Biotechnology, Southern Medical University, Guangzhou 510515, People's Republic of China \\ ${ }^{5}$ Cancer Research UK Molecular Oncology Laboratories, Weatherall Institute of Molecular Medicine, John Raddliffe Hospital, University of Oxford, \\ Oxford OX3 9DS, UK
}

*Correspondence to: Jian-Ming Li and Yan-Qing Ding, Department of Pathology and Guangdong Provincial Key Laboratory of Molecular Tumour Pathology, Southern Medical University, Guangzhou 510515 , People's Republic of China. E-mail: lixinyue@fimmu.com or dyq@fimmu.com

$\dagger$ These authors contributed equally to this work.

No conflicts of interest were declared.

Received: I 5 July 2009

Revised: 5 November 2009

Accepted: 27 November 2009

\begin{abstract}
To understand the molecular mechanisms of metastasis and prognosis of colorectal cancer (CRC), we isolated single cell-derived progenies (SCPs) from SW480 cells in vitro and compared their metastatic potential in an orthotopic CRC tumour model in vivo. Two groups of SCPs with the capability of high and low metastasis, respectively, were obtained. By analysing the gene expression profiles of high (SCP51), low (SCP58) metastatic SCPs, and their parental cell line (SW480/EGFP), we demonstrated that 143 genes were differentially expressed either between SCP51 and SCP58 or between SCP58 and SW480/EGFP. Geneannotation enrichment analysis of DAVID revealed 80 genes in the top ten clusters of the analysis (gene enrichment score $>1$ ). Of the 80-gene set, 32 genes are potentially involved in metastasis, as revealed by Geneclip. Five putative metastatic genes $(L Y N, S D C B P, M A P 4 K 4$, DKK1, and $M I D 1$ ) were selected for further validations. Immunohistochemical analysis in a cohort of $181 \mathrm{CRC}$ clinical samples showed that the individual expression of LYN, MAP4K4, and MID1, as well as the five-gene signature, was closely correlated with lymph node metastasis in CRC patients. More importantly, the individual expression of LYN, MAP4K4, SDCBP, and MID1, as well as the five-gene signature, was significantly correlated with overall survival in CRC patients. Thus, our five-gene signature may be able to predict metastasis and survival of CRC in the clinic, and opens new perspectives on the biology of CRC.

Copyright (c) 2009 Pathological Society of Great Britain and Ireland. Published by John Wiley \& Sons, Ltd.
\end{abstract}

Keywords: single cell-derived progenies; gene signature; prognosis; metastasis; colorectal cancer

\section{Introduction}

Metastasis is the main cause leading to death of colorectal cancer (CRC) patients. However, the molecular mechanisms of metastasis of CRC remain largely unknown. The discovery of novel biomarkers has relevance for the early diagnosis, prevention, and possible target therapy of CRC patients, as well as providing new biological insights. Microarray profiling has been shown to be a valuable technique to uncover biomarkers or prognosis factors for patients with different types of cancer [1-5]. A gene expression signature, defined as the expression pattern of a particular set of genes, has been widely used in identification of the specific cancer type or subtype, prediction of the outcome of patients, and selection of the appropriate therapeutic treatment [6-8].
Two common strategies based on the gene expression profiling technique have been used to identify novel biomarkers associated with many characteristics of cancer. Profiling of human tissue can distinguish the gene expression between normal and tumour tissues from patients. This approach usually results in large numbers of such genes and only a small proportion of these genes may be clinically useful. The second strategy is based on the notion that only a few cells from a heterogeneous population have metastatic capability. Therefore, metastatic variants can be isolated from the primary bulk of the tumour. In vivo selection has been used to discern genetic determinants of metastasis. Using this approach, Massague and co-workers have reported gene signatures mediating breast cancer metastasis to bone [9], lung [10], and brain [11] The molecular signatures derived from mouse tumour 
models could successfully predict the progression and prognosis of breast cancer.

In this study, we isolated single cell-derived progenies (SCPs) with different metastatic potentials from the SW480 cell line in vitro and compared their gene expression profiles in vivo. We identified a 32-gene set as the candidate genes associated with metastasis of CRC by cross-comparing, functional analysis and gene annotation, and text mining. In a cohort of 181 CRC clinical samples, we validated the expression of a five-gene signature and each of the five genes in CRC. We found that the five-gene signature may be able to predict metastasis and patient survival of CRC.

\section{Materials and methods}

\section{Cell culture}

The human CRC cell line SW480 was obtained from the Cell Bank at the Chinese Academy of Sciences (Shanghai, China). SW480/EGFP was established from SW480 by transfection of pEGFP-N1 plasmid. Tumour cells were cultured in RPMI 1640 medium (Gibco, Grand Island, NY, USA) supplemented with $10 \%$ fetal bovine serum (Hyclone, Logan, UT, USA) and $100 \mathrm{U} / \mathrm{ml}$ penicillin/streptomycin (Gibco), and incubated in a humidified chamber with $5 \% \mathrm{CO}_{2}$ at $37^{\circ} \mathrm{C}$. SW480/EGFP cells were diluted in medium at $2-10$ cells $/ \mathrm{ml}$. $100 \mu \mathrm{l}$ of the dilution was added to each well of a 96-well plate. Wells containing a single clone derived from one cell were identified under a microscope (Figure 1A). Clones were then expanded in $10-\mathrm{cm}$ tissue culture plates.

\section{Cell proliferation assay}

Tumour cells were prepared at a concentration of $1 \times 10^{3}$ cells $/ \mathrm{ml}$. Aliquots $(200 \mu \mathrm{l})$ of the cells were dispensed in triplicate into 96-well plates. After indicated days, $20 \mu \mathrm{l}$ of 3-(4,5-dimethylthiazol-2-yl)2,5-diphenyltetrazolium bromide (MTT) $(5 \mathrm{mg} / \mathrm{ml}$; Promega) was added to each well. Four hours later, the supernatant was removed and $150 \mu$ l of dimethyl sulphoxide (Sigma, St Louis, MO, USA) was added. After 15-min incubation, the absorbance value (OD) was measured at $570 \mathrm{~nm}$ in a micro-plate reader. Four independent experiments were performed.

\section{Tumour xenografts}

Xenograft tumours were generated by subcutaneous injection of $5 \times 10^{6}$ cells on the flanks of nude mice. Orthotopic implantation of the tumour fragment obtained from the subcutaneous tumour to the caecum was performed (Supporting information, Supplemental experimental procedures) as described previously [12]. To observe tumour growth, fluorescence emitted by tumour cells was imaged by a whole-body green fluorescence protein (GFP) imaging system (Lighttools, Encinitas, CA, USA). Images were then analysed to calculate the tumour area and tumour growth using IPP5.0 software (Cybermetics Co, Silver Spring, MD, USA). To dissect tumour metastasis, various organs were collected from the tumour-bearing mice. The samples was fixed in $10 \%$ neutral buffered formalin, embedded in paraffin, and stained with haematoxylin and eosin.

\section{Microarray analysis}

Nine samples, three from parental SW480/EGFP, three from SCP51 with high metastatic potential, and three from SCP58 with low metastatic potential, were collected. Total RNA was extracted from the samples using a Qiagen RNeasy kit (Qiagen, Chatsworth, CA, USA). The Affymetrix Human Genome U133 Plus 2.0 Array GeneChips (Affymetrix, Santa Clara, CA, USA) were used for microarray analysis. Hybridization and scanning of the genechips were performed by the CapitalBio Biotechnology Company (Beijing, China) according to the standard Affymetrix protocol (Supporting information, Supplementary experimental procedures). The data have been deposited in the public Gene Expression Omnibus repository (Accession number GSE16934). Significance analysis of microarrays (SAM) was performed to identify the genes expressed differentially between SCP51 and SCP58, or between SCP58 and SW480/EGFP. Common differential genes were obtained by cross-comparing the two data sets.

\section{Functional analysis and gene annotation}

The Database for Annotation, Visualization, and Integrated Discovery (DAVID) was used to discover enriched function-related gene groups by geneannotation enrichment analysis (http://david.abcc. ncifcrf.gov/). The genes in the top ten clusters (gene enrichment score $>1$ ) from the gene-annotation enrichment analysis were selected. Geneclip [13], a software program for clustering gene lists by literature profiling and constructing gene co-occurrence networks, was used to acquire a primary profile of known genes related to metastasis in colorectal cancer, melanoma, and other cancers.

\section{Reverse transcription-polymerase chain reaction (RT-PCR)}

RT-PCR was performed to measure the expression of LYN, SDCBP, MAP4K4, MID1, and DKK1 at the mRNA level in fresh colorectal tumour samples. Total RNA was extracted from the tumour using Trizol reagent (Invitrogen, Carlsbad, CA, USA) according to the manufacturer's instructions. RNA was treated with DNase and used for cDNA synthesis with random hexamers. The primers used for amplifying LYN, SDCBP, MAP4K4, MID1, and DKK1 have been described in the Supporting information, Supplemental experimental procedures. 


\section{Western blot analysis}

Mouse monoclonal antibodies to DKK1, MAP4K4, and MID1, and rabbit polyclonal antibodies to LYN and SDCBP were purchased from Abcam (Cambridge, UK). Procedural details of western blotting have been described in the Supporting information, Supplemental experimental procedures.

\section{Immunohistochemical staining and scoring}

Formalin-fixed, paraffin-embedded colorectal tumour samples obtained from patients at the Nanfang Hospital of Southern Medical University (Guangzhou, China) were used in our clinicopathological investigation. Individual consent on use of the clinical sample for research purposes was obtained from each patient and approved by the Ethical Committee of Southern Medical University. Histological classification and clinicopathological staging of the tumours were performed according to the Japanese General Rules for Clinical and Pathological Studies on Cancer of the Colon, Rectum, and Anus, along with the International Union Against Cancer Classification. Immunohistochemical staining was performed using a Dako EnVision System (Dako, Carpentaria, CA, USA) following the protocol recommended by the manufacturer to study the expression of LYN, SDCBP, MAP4K4, MID1, and DKK1 in 181 clinical samples. Mouse anti-MAP4K4 monoclonal antibody $(1: 100$; Sigma-Aldrich, St Louis, USA), rabbit anti-human MID1 polyclonal antibody (1:50; Abnova, Taiwan), rabbit anti-human SDCBP $(1: 25)$, LYN $(1: 50)$, and DKK1 $(1: 10)$ polyclonal antibodies (Abcam, Cambridge, UK) were used in the study. The stained tumours were reviewed and scored separately by two pathologists blinded to the patients' clinical characteristics. Scoring of the tumour staining was performed as described previously $[14,15]$. Briefly, the intensity of staining was scored as negative (0), weak (1), medium (2), or strong (3). The extent of staining, defined as the percentage of positive staining areas in relation to the whole tumour section, was scored as $0(0 \%), 1$ (1-25\%), 2 (26-50\%), $3(51-75 \%)$, or $4(76-100 \%)$. An overall expression score, ranging from 0 to 12, was calculated by multiplying the score of intensity and that of extent.

For statistical analysis, a final score number $\geq 4$ was considered high expression of the protein of interest. The score for the five-gene signature was calculated from the value of each gene in the signature. Since upregulation of LYN, SDCBP, and MAP4K4 contributed to the progression of CRC, high expression was scored as 1 , while low expression was scored as 0 for these genes. However, since down-regulation of MID1 and DKK1 was also associated with CRC progression, for these genes low expression was scored as 1 , while high expression was scored as 0 . The sum of the scores for the five proteins was regarded as the score of the fivegene signature. For statistical analysis, a final score $\geq 3$ was considered to be positive expression of the five-gene signature.

\section{Statistical analysis}

Statistical analyses were performed using the SPSS software program (version 12.0; SPSS Inc, Chicago, IL, USA) and the results were confirmed by statisticians in the Department of Health Statistics, Southern Medical University. The chi-square test was used to assess differences in metastasis and peritoneal dissemination of tumour cells. The Mann-Whitney $U$ test was used to analyse the relationship between the expression of LYN, SDCBP, MAP4K4, MID1, DKK1 or the five-gene signature and clinicopathological characteristics of the patients. Survival curves for the patients with different expression of LYN, SDCBP, MAP4K4, MID1, and DKK1 were plotted using the Kaplan-Meier method and compared using the logrank test. The significance of various survival-related variables was assessed using the Cox proportional hazards model in a multivariate analysis. In vitro proliferation assay, in vivo tumour growth assay, cell motility assay, and metastatic potentials of SCPs were tested using ANOVA. Statistical significance was concluded where $p \leq 0.05$ and is denoted in the figures by an asterisk.

\section{Results}

Isolation and metastatic characterization of single cell-derived progenies

A total of 59 SCPs were isolated from SW480/EGFP. Subcutaneous implantation of SCPs on flanks of nude mice showed that 29 SCPs (SCP3, SCP5, SCP8, SCP9, SCP10, SCP11, SCP12, SCP15, SCP20, SCP21, SCP23, SCP27, SCP28, SCP30, SCP31, SCP32, SCP33, SCP34, SCP35, SCP36, SCP37, SCP38, SCP43, SCP44, SCP50, SCP51, SCP55, SCP57, and SCP58) exhibit the capacity of tumourigenicity to produce a visible tumour (Figures 1B and 1C). SCPs that formed a subcutaneous tumour in $\geq 3$ out of seven mice were selected for further study. The ability of an individual SCP to grow as a tumour under the skin of nude mice was shown to be significantly different $(F=33.446, p=0.000)$ (Supporting information, Supplementary Table 1).

To mimic human colorectal cancer, seven SCPs were orthotopically implanted into the caecum individually. Dissection of the metastasis in several commonly metastasized sites including the peritoneal cavity, lymph node, and liver demonstrated that SCPs could be categorized into two groups based on their metastatic potential. SW480/EGFP, SCP12, SCP21, and SCP51 exhibited high metastatic potential, while SCP11, SCP28, and SCP58 had low metastatic potential (Figure 2A). To confirm the metastatic characteristics, orthotopic xenografts were performed again for SCP21, SCP51, SCP28, and SCP58. As shown in 


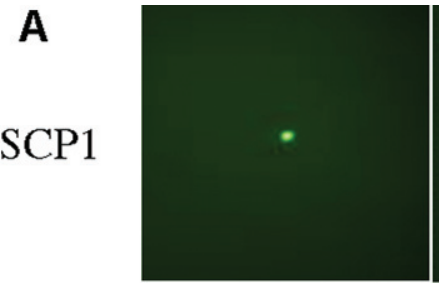

$1 \mathrm{~d}$

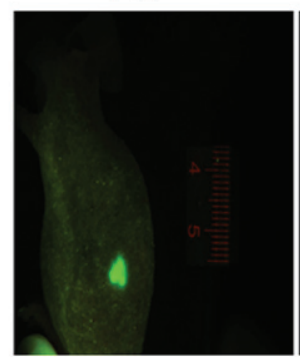

14d

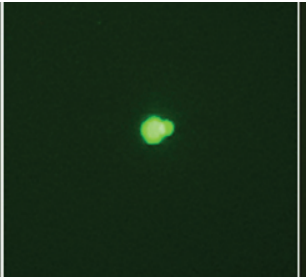

$2 d$

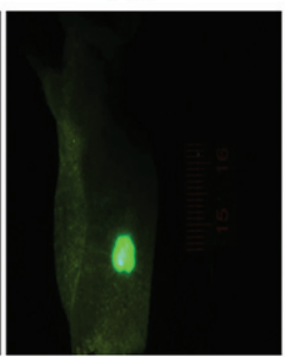

21d

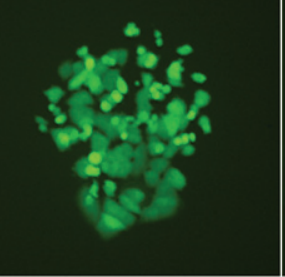

$7 d$

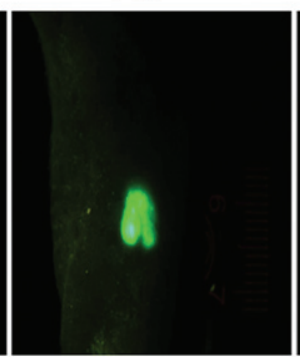

28d

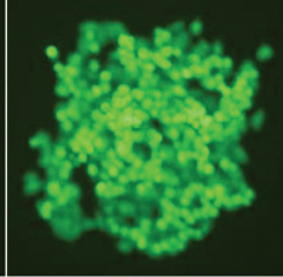

1d

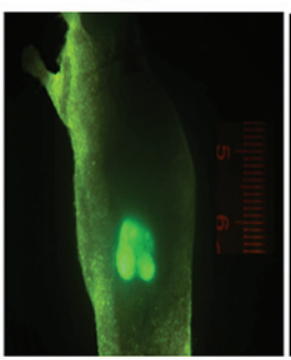

$35 d$

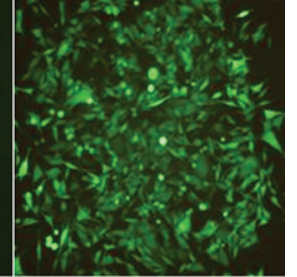

$14 d$

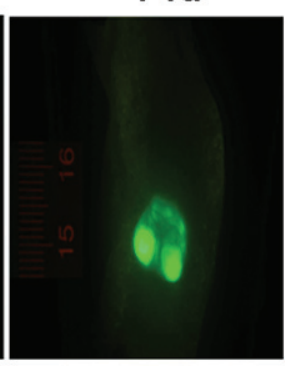

$42 d$

C

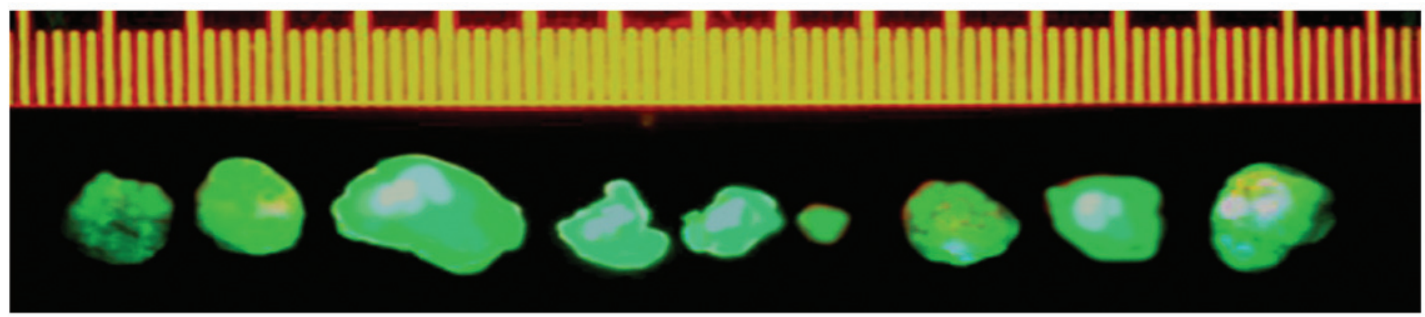

SCP3 SCP20 SCP10 SCP28 SCP58 SCP11 SCP9 SW480/EGFP SCP51

Figure I. Single cell-derived progenies (SCPs) were isolated from SW480/EGFP. (A) In vitro growth and clonal formation of SCPI observed under a fluorescent microscope. (B) Whole-body optical images of the SCP3 tumour that grew subcutaneously on the flanks of nude mice. (C) Tumour samples of SCP3, SCP20, SCPI0, SCP28, SCP58, SCPII, SCP9, SCP5I, and SW480/EGFP collected after subcutaneous growth on the flanks of nude mice for 5 weeks

Figure 2B, SCP21 and SCP51 were the high metastatic variants, whereas SCP28 and SCP58 were the low metastatic variants. The enhanced metastasis of SCP51 in lymph node and liver is demonstrated in Figures 2C and $2 \mathrm{D}$.

In vitro proliferation, in vivo tumour growth, and migration of SCP5I, SCP58, and SW480/EGFP

Next, we assessed the proliferation and migration capabilities of the SCPs. As shown in Figures 3A and $3 \mathrm{~B}$, both in vitro and in vivo SCP51 grew faster than SW480/EGFP, while SCP58 proliferated more slowly than SW480/EGFP. In vitro wound-healing migration assay showed that after $72 \mathrm{~h}$, SCP51 cells filled in about $80 \%$ of the scratched area, whereas SCP58 cells filled in only about $20 \%$ of the scratched area (Figure 3C). Cell cycle analysis of SCP51, SCP58, and SW480/EGFP cells by flow cytometry demonstrated that the cell number of the G1 phase and the proliferative index (the percentage of $\mathrm{S}+\mathrm{G} 2$ nuclei in the DNA histogram) of SCP51 were significantly increased compared with those of SW480/EGFP or SCP58 (Supporting information, Supplementary Table 2).

\section{Identification of 32 candidate genes with metastatic potential}

To investigate the molecular signature underlining the enhanced metastasis, we then carried out microarray analysis using Affymetrix human genechips. Several approaches were used to identify the candidate genes mediating CRC metastasis (Figure 4A). First, we screened the genes expressed differentially between SCP51 and SCP58 (SCP51 versus SCP58), or between SCP58 and SW480/EGFP (SW480/EGFP versus SCP58), using SAM with a false-discovery rate of $4 \%$. A total of 439 genes (derived from 612 probes), with 229 up-regulated and 210 downregulated, were found to be differentially expressed between SCP51 and SCP58 (Supporting information, Supplementary Table 3). Similarly, a total of 313 genes (from 359 probes), with 153 up-regulated and 160 down-regulated, were differentially expressed between SW480/EGFP and SCP58 (Supporting information, Supplementary Table 4). Next, we crosscompared the 439 genes expressed differentially between SCP51 and SCP58 with the 313 genes expressed differentially between SCP58 and SW480/ EGFP. 143 genes were found to have metastatic potential (Figure 4B and Supporting information, 


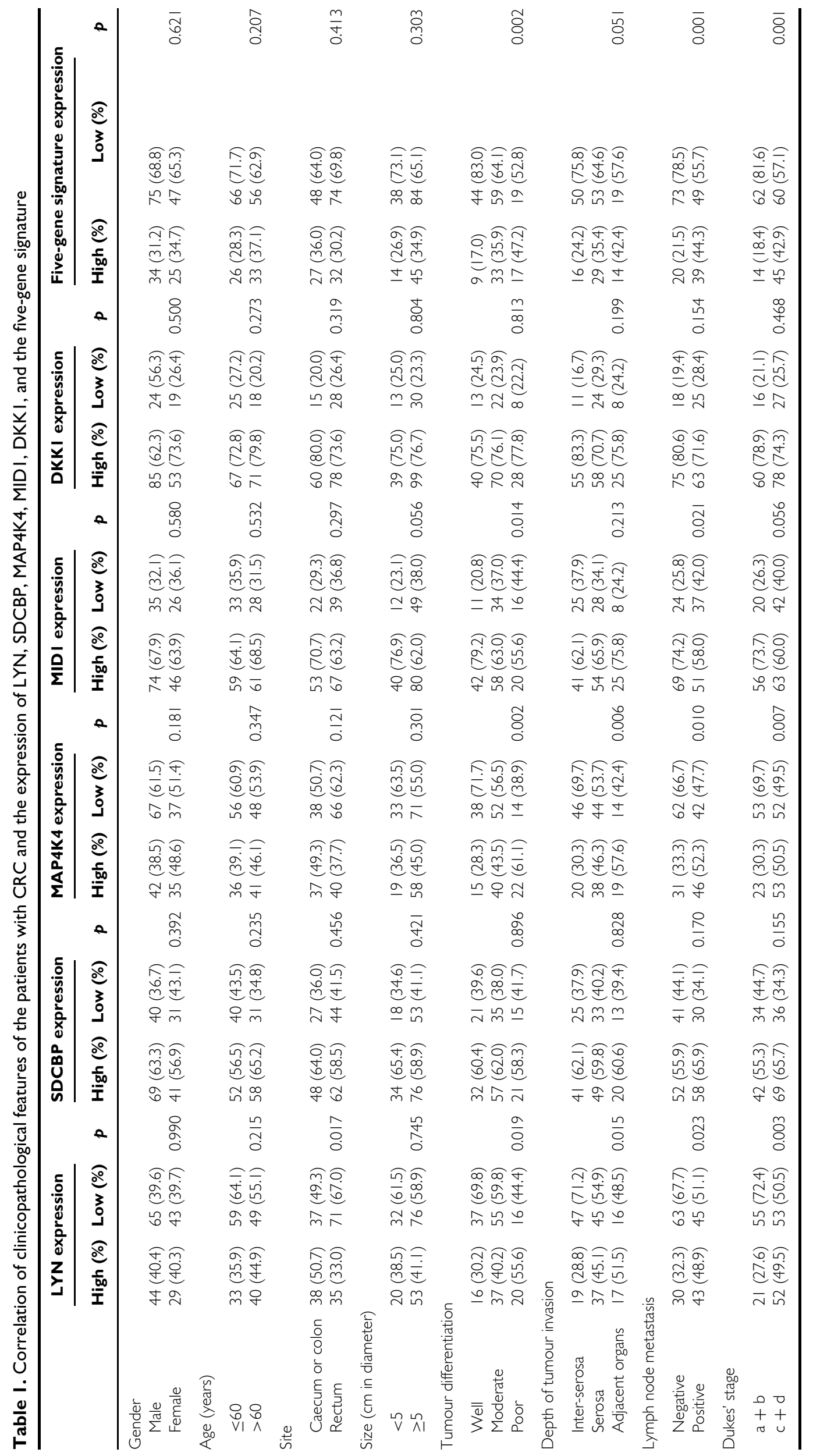



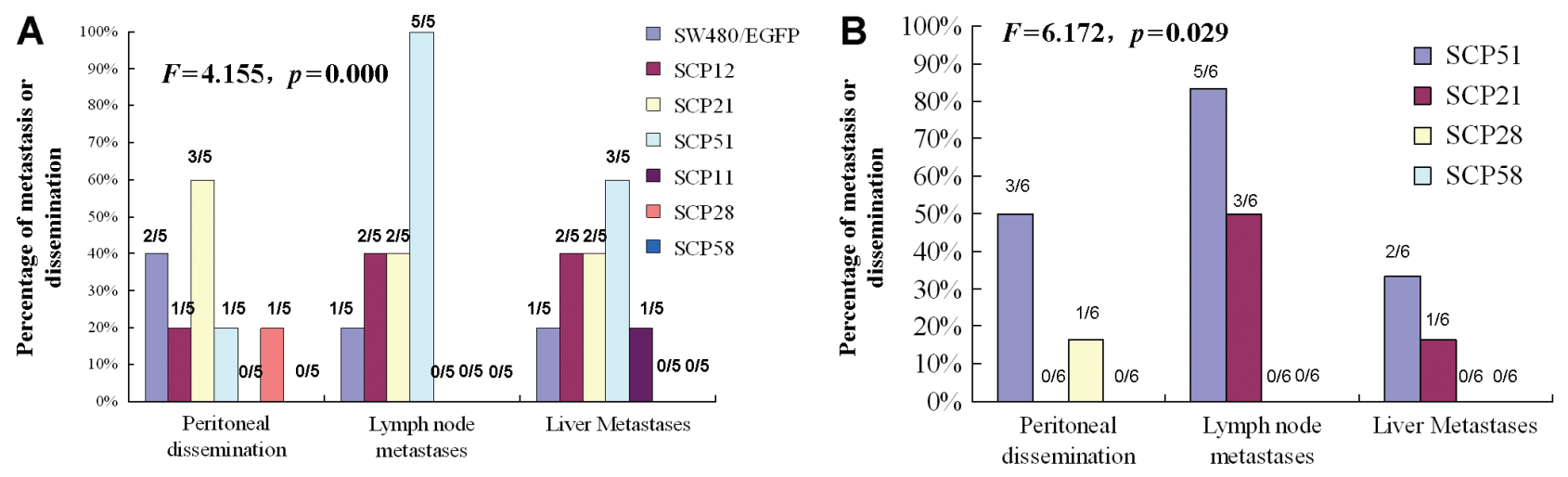
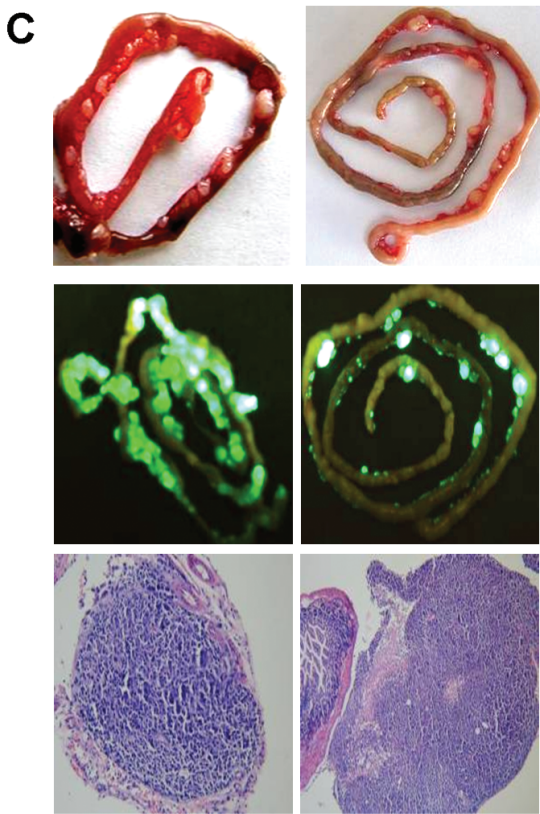

Mice \#1

SCP51 with enhanced metastatic potential to lymph
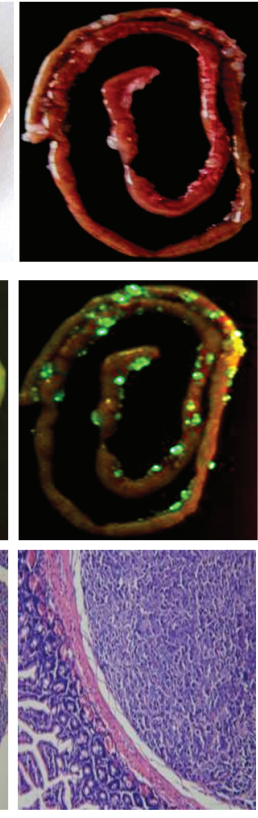

Mice \# 5
D
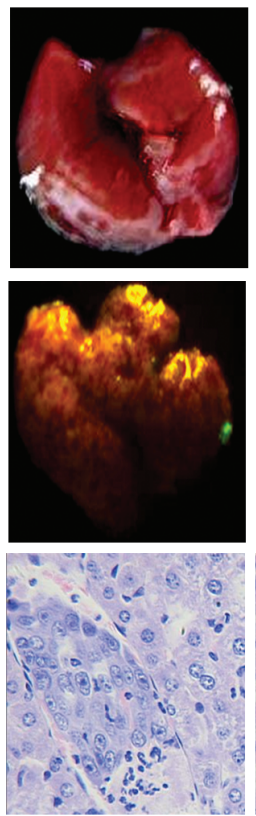

Mice \#1
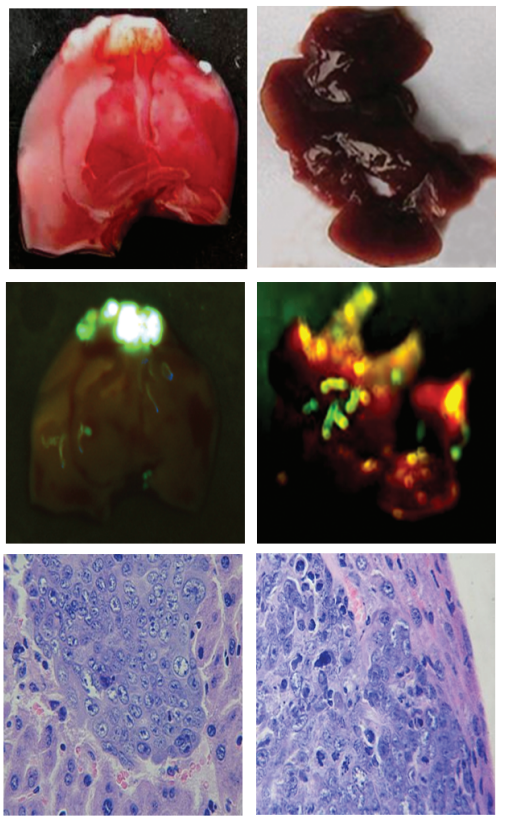

Mice \#2

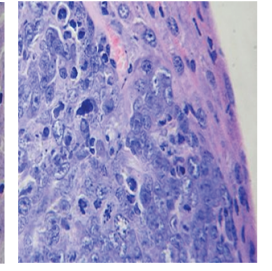

Mice \# 5

SCP51 with enhanced metastatic potential to liver

Figure 2. Spontaneous metastasis of SCPs in lymph node and liver, and peritoneal dissemination in orthotopic xenograft models. (A) Spontaneous metastasis and peritoneal dissemination of SCPI2, SCP2I, SCP5I, SCPII, SCP28, SCP58, and SW480/EGFP. (B) Spontaneous metastasis and peritoneal dissemination of SCP5I, SCP2I, SCP28, and SCP58. (C) Whole-body optical images of lymphatic metastasis of SCP5I in the orthotopic mouse model. Lymphatic metastasis was confirmed by histological analyses. (D) Whole-body optical images of liver metastasis of SCP5I in the orthotopic mouse model. Liver metastasis was confirmed by histological examinations

Supplementary Table 5). We then further analysed these genes using the gene-annotation enrichment analysis of DAVID (gene enrichment score $>1$ ) and found that 80 genes were enriched in the top ten clusters (Supporting information, Supplementary Tables 6 and 7). Finally, we analysed the potential functions of these 80 genes by using Geneclip, a text-mining program.

Thirty-two genes were found to be closely associated with metastasis. These genes are known to be involved in several important pathways, such as transcription regulation (SMARCA2, FOXO1A, HOXB8, etc), development (SEMA3A, MSX1, COL6A3, etc), cell motility (MARCKS, JAG1, $T H B S 1$, etc), and signal transduction ( $L Y N, V D R$, $S A V 1$, etc) (Supporting information, Supplementary Table 8). As shown in Figure 4C, SCP51, SCP58, and $S W 480 / E G F P$ were clearly clustered into three subgroups based on their metastatic potential using the 32-gene set. The literature profiling and constructing gene co-occurrence networks of the 32gene set by the Geneclip analysis suggested that these 32 genes had important roles in metastasis (Figure 4D). A primary co-occurrence network between the 32-gene set and metastasis, colorectal cancer, melanoma, and other cancers further highlighted the potential of these genes in tumour metastasis (Figure 4E).

\section{Validation of the expression of LYN, SDCBP, MAP4K4, DKKI, and MIDI in the primary} tumours

We selected LYN, SDCBP, MAP4K4, DKK1, and MID1 from the 32-gene set for further investigations since their roles in CRC were unclear. Both 


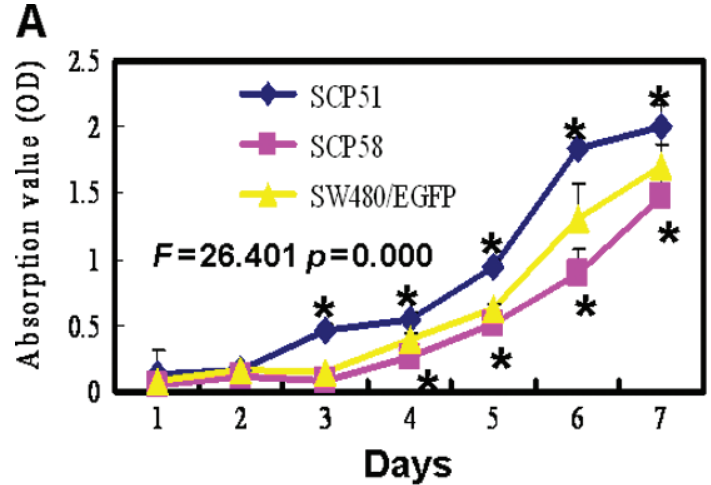

$* p<0.05$ vs. SW480/EGFP
B

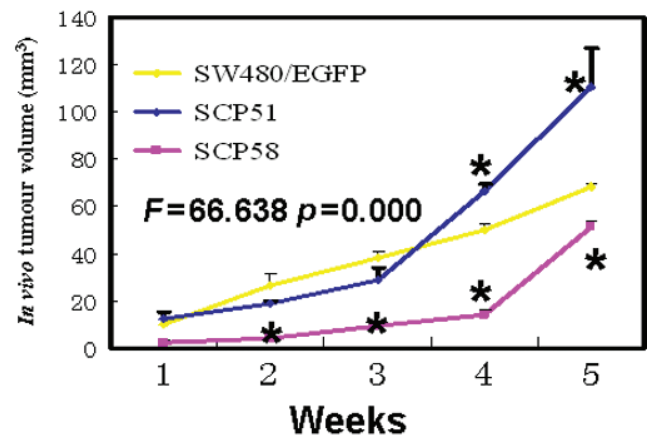

$* p<0.05$ vs. SW480/EGFP

\section{C}

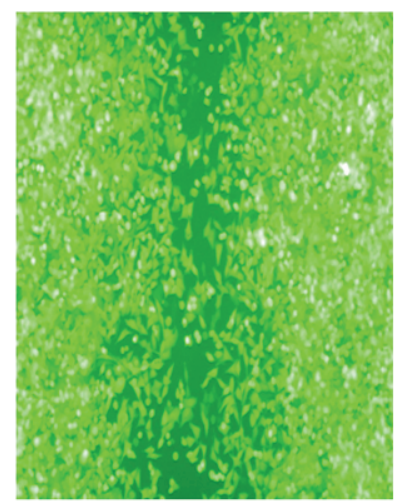

SCP51

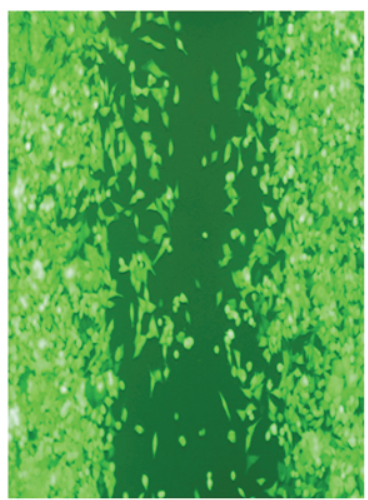

SCP58

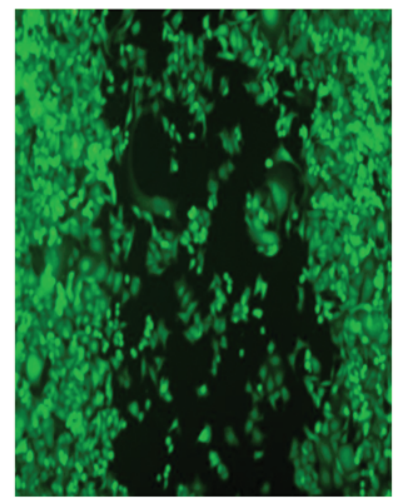

SW480/EGFP

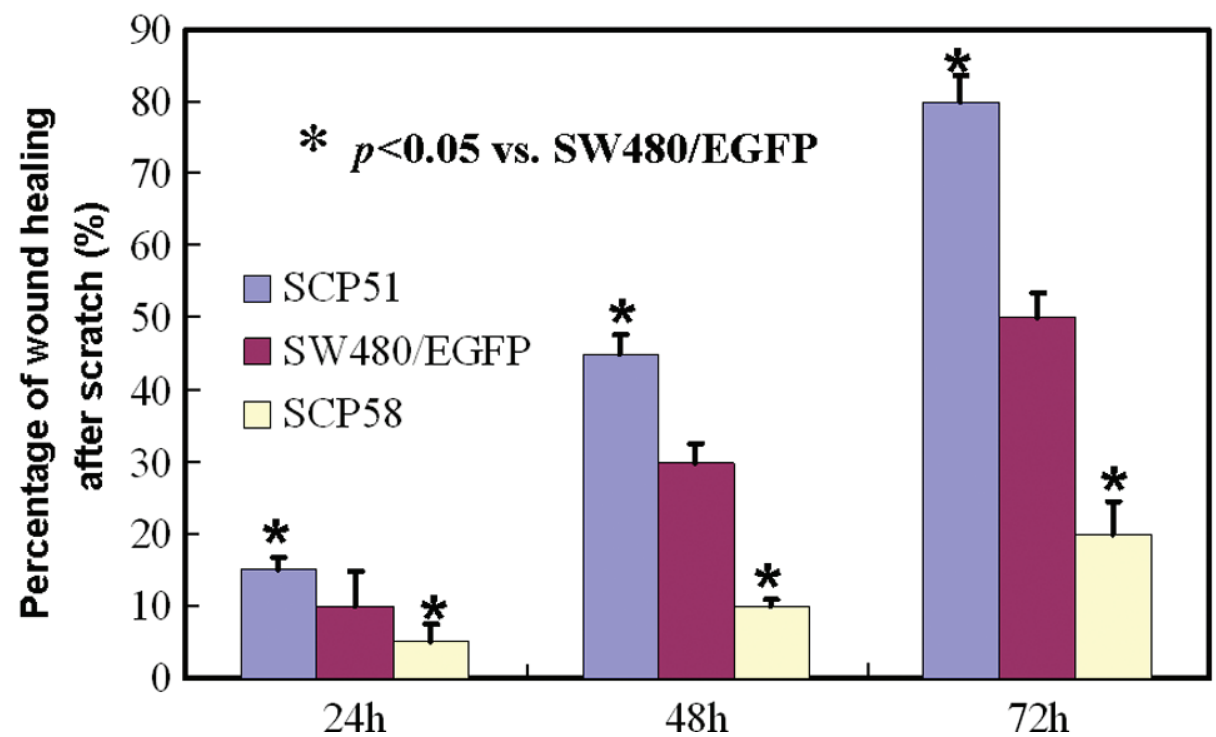

Figure 3. In vitro proliferation, in vivo tumour growth, and migration of SCP5I, SCP58, and SW480/EGFP. (A) In vitro growth of SCP5I and SCP58 cells and SW480/EGFP. The values represent the absorbance value (OD) detected by MTT assay. (B) Subcutaneous growth of the tumours of SCP58, SCP5I, and SW480/EGFP on the flanks of nude mice. Each value represents the mean \pm SD of the tumour volume. (C) Cell migration of SCP5I, SCP58, and SW480/EGFP for $72 \mathrm{~h}$ in a scratch wound-healing assay

RT-PCR and western blotting were used to validate their expression in fresh CRC samples. As shown in Figure 5, compared with that of the paired normal tissues, the expression of LYN and SDCBP was increased in most of the tumours at both mRNA and protein levels. In contrast, the expression of DKK1 was decreased in most of the tumours. For MID1, the expression of mRNA and protein of $75 \mathrm{kD}$, but not $34 \mathrm{kD}$, was decreased in most of the tumours. MID1 is known to be associated with microtubules as a homodimer [16], and thus the $75 \mathrm{kD}$ protein is presumably the homodimer. The mRNA expression of MAP4K4 was increased in the primary tumours, consistent with the array result; however, the protein level 
Table 2. Summary of univariate and multivariate Cox regression analysis of overall survival duration

\begin{tabular}{|c|c|c|c|c|c|c|}
\hline \multirow[b]{2}{*}{ Variable } & \multicolumn{3}{|c|}{ Univariate } & \multicolumn{3}{|c|}{ Multivariate } \\
\hline & HR & $\mathrm{Cl}(95 \%)$ & $p$ & HR & $\mathrm{Cl}(95 \%)$ & $p$ \\
\hline Gender & -0.066 & $-0.507-0.375$ & 0.770 & & & \\
\hline Age & 0.012 & $-0.004-0.028$ & 0.151 & & & \\
\hline DKKI & -0.376 & $-0.850-0.098$ & 0.120 & & & \\
\hline SDCBP & 0.446 & $-0.013-0.905$ & 0.056 & & & \\
\hline LYN & 0.719 & $0.290-1.148$ & $0.001 *$ & & & \\
\hline MAP4K4 & 0.477 & $0.048-0.906$ & $0.029^{*}$ & & & \\
\hline Differentiation & 0.559 & $0.251-0.867$ & $0.000^{*}$ & 0.317 & $0.979-1.926$ & 0.066 \\
\hline Dukes' stage & 1.025 & $1.710-4.538$ & $0.000^{*}$ & 0.669 & $|.172-3.25|$ & $0.010^{*}$ \\
\hline MIDI & -0.712 & $-1.145--0.279$ & $0.001^{*}$ & -0.498 & $0.391-0.945$ & $0.027^{*}$ \\
\hline Five-gene signature & 1.183 & $0.752-1.614$ & $0.000 *$ & 0.888 & $1.550-3.812$ & $0.000 *$ \\
\hline
\end{tabular}

$* p<0.05$

was decreased in most of the primary tumours, suggesting post-transcriptional modifications of MAP4K4 in the tumour.

\section{Correlation of gene expression with clinicopathological characteristics of the CRC patients}

To further investigate the role of $L Y N, S D C B P$, $M A P 4 K 4, D K K 1$, and $M I D 1$ in colorectal tumour metastasis, we measured the protein levels of these genes in 181 archived paraffin-embedded CRC samples using immunohistochemical staining (Figure 6) and analysed the correlation of the clinicopathological characteristics of these patients with the expression of $L Y N, S D C B P, M A P 4 K 4, D K K 1, M I D 1$, and the five-gene signature. As summarized in Table 1, there were no significant associations of either individual expression of $L Y N, S D C B P, M A P 4 K 4, D K K 1$, and $M I D 1$, or the expression of the five-gene signature with age or gender of the patients $(p>0.05)$. However, we found that expression of $L Y N, M A P 4 K 4$, $M I D 1$, and the five-gene signature correlated closely with tumour differentiation and lymph node metastasis (Table 1). In addition, expression of $L Y N, M A P 4 K 4$, and the five-gene signature was significantly associated with Dukes' stage $(p<0.01)$. Moreover, expression of $L Y N$ and $M A P 4 K 4$ correlated significantly with tumour invasion $(p<0.05)$, although the fivegene signature did not correlate well with tumour invasion $(p=0.051)$.

\section{Survival analysis and log-rank test results}

To investigate the prognostic value of MAP4K4, LYN, $S D C B P, D K K 1, M I D 1$, and the five-gene signature for $\mathrm{CRC}$, we evaluated the association of individual expression of $M A P 4 K 4, L Y N, S D C B P, D K K 1$, and $M I D 1$, and expression of the five-gene signature, with the survival rate using Kaplan-Meier analysis with the log-rank test. As shown in Figures 7A-7E, expression of $M A P 4 K 4, L Y N, S D C B P$, and $M I D I$ was found to correlate significantly with the overall survival of patients. Notably, the five-gene signature also correlated highly with the overall survival of patients (Figure 7F). Clearly, the correlation of the five-gene signature with patient survival was much better than any single gene (see Figures $7 \mathrm{~A}-7 \mathrm{~F}$ ).

To determine whether the expression of the fivegene signature acts as an independent prognostic factor for CRC, we performed multivariate survival analysis of the expression of the five-gene signature with numerous factors such as gender, age, tumour differentiation, Dukes' classification, and individual expression of the five genes. As shown in Table 2, Dukes' classification and the expression of MID1 and the five-gene signature were independent prognostic factors for CRC patients, of which the five-gene signature was the best prognostic factor $(p<0.001)$.

\section{Discussion}

In this study, we isolated SCPs from the SW480 cell line in vitro and assessed their ability to grow subcutaneously on the flanks of nude mice. Less than $50 \%$ of the SCPs (29/59) were capable of forming visible tumours in vivo and the growth traits of the SCPs were shown to be significantly different. Two groups of SCPs that exhibited the capability of either high or low metastasis were separated by orthotopic implantation of SCP cells in nude mice. Because the difference of gene profiling between the high and the low metastatic SCPs may be clinically relevant, we performed microarray analyses to excavate the molecules that drove the metastasis.

We used several approaches to identify the genes involved in CRC metastasis. First, we screened the genes expressed differentially between the high and the low metastatic SCPs. We then cross-compared the differential genes expressed between SCP51 and SCP58 with those found between SCP58 and SW480/ EGFP, and obtained the common genes associated with CRC metastasis. Moreover, we picked the enriched genes from the common genes by using the gene-annotation enrichment analysis of DAVID. Finally, we used Geneclip, text-mining software developed in our laboratory, to find the genes associated 


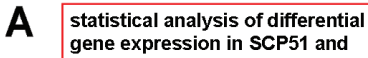
SCP58 cells statistical analysis of

differential gene expression

80/EGFP

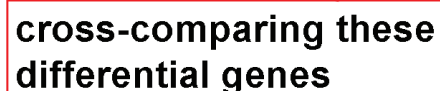

143-gene set

DAVID Gene-annotation enrichment analysis

80 -gene set

\section{Geneclip text mining analysis}

\section{2-gene set}

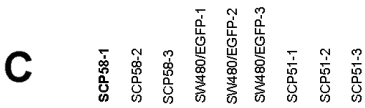

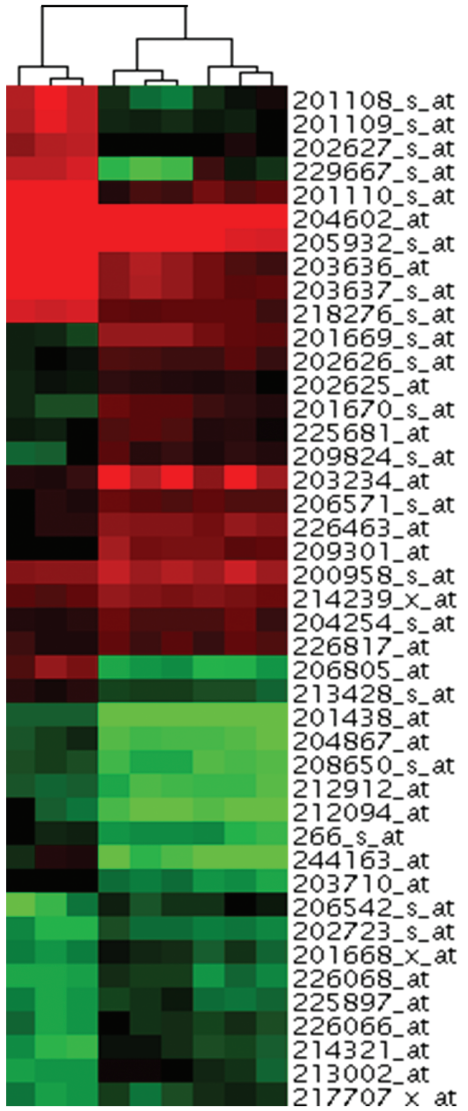

D
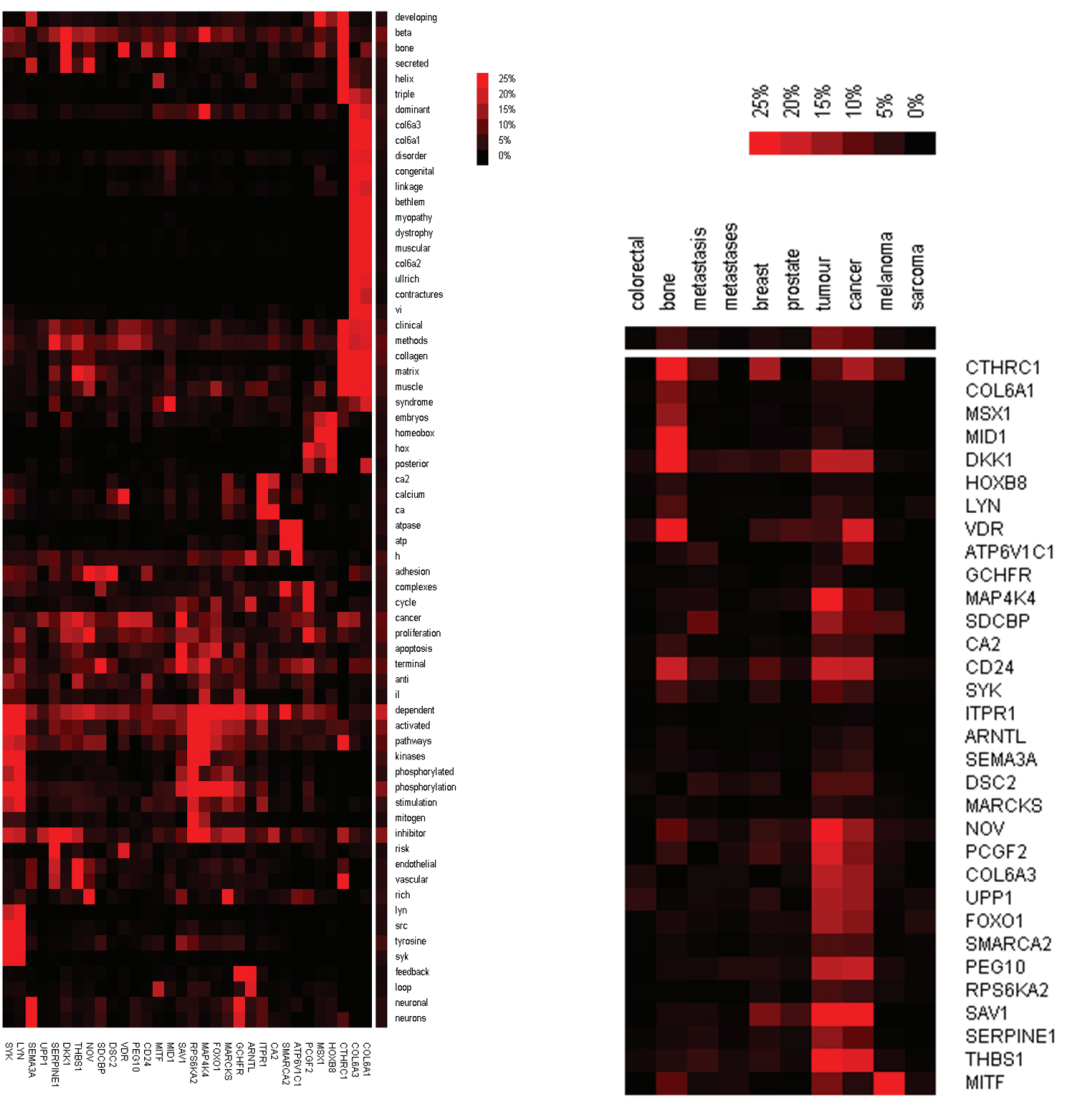

CTHRC1
COL6A1
MSX1
MID1
DKK1
HOXB8
LYN
VDR
ATP6V1C1
GCHFR
MAP4K4
SDCBP
CA2
CD24
SYK
ITPR1
ARNTL
SEMA3A
DSC2
MARCKS
NOV
PCGF2
COL6A3
UPP1
FOX01
SMARCA2
PEG10
RPS6KA2
SAV1
SERPINE 1
THBS1

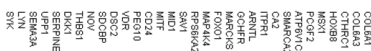

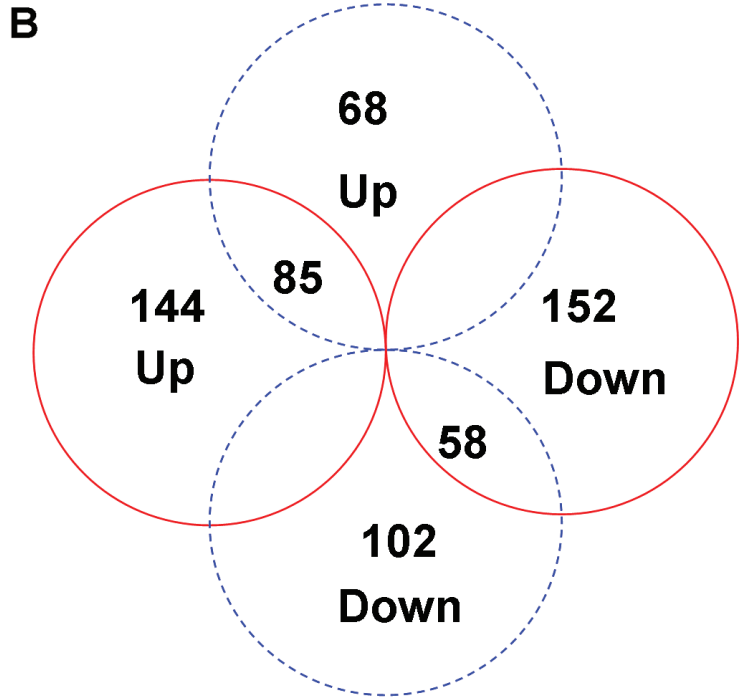

SCP51 /SCP58

SW480/EGFP/SCP58

Figure 4. 32 candidate genes with metastatic potential were identified by microarray analyses. (A) A workflow of the strategy for identification of the genes associated with CRC metastasis. (B) Venn diagrams of the common differential genes identified by cross-comparing the genes expressed differentially between SCP5I and SCP58 cells, or between SCP58 and SW480/EGFP. (C) Hierarchical cluster diagram of 32 differentially expressed genes in SCP5I, SCP58 cells, and SW480/EGFP. (D) Hierarchical cluster diagram of the 32-gene set based on literature profiling and constructing gene co-occurrence networks using default indicators of Geneclip. (E) A primary co-occurrence network between the 32-gene set and metastasis, colorectal cancer, melanoma, and other cancers by the Geneclip analysis

with metastasis. We successfully reduced the number of candidate genes from 143 to 32 . The strategy is straightforward and without any complex calculations, and is thus adaptable for use in other studies. 
A
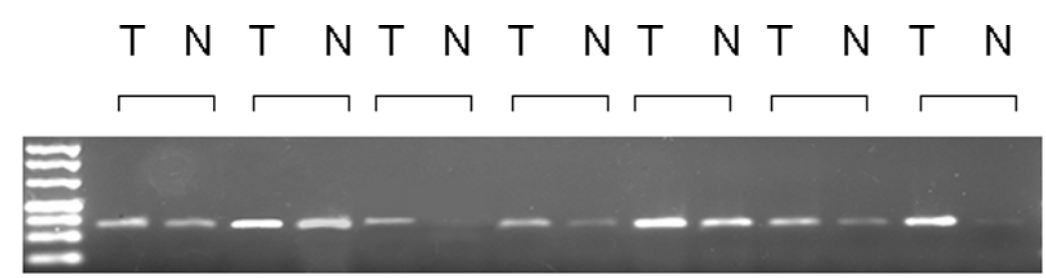

MAP4K4

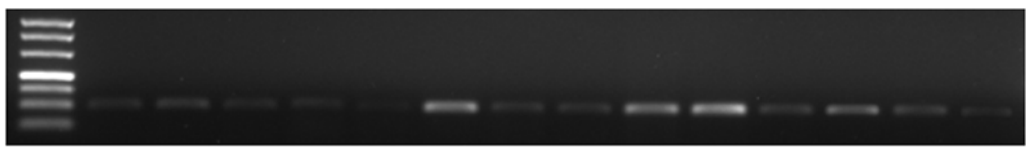

DKK1

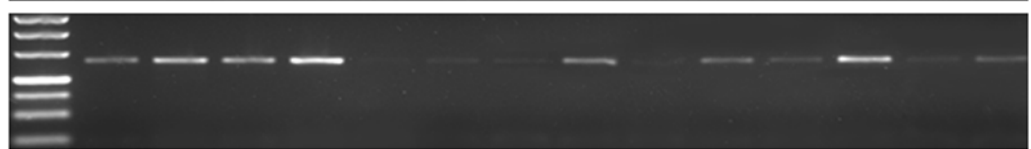

MID1

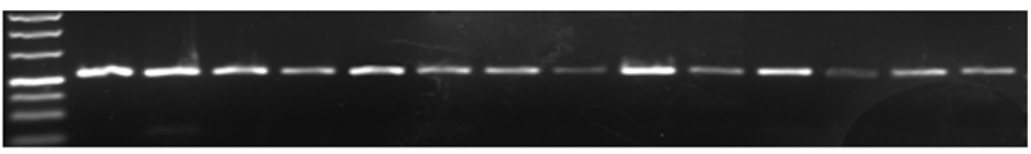

LYN

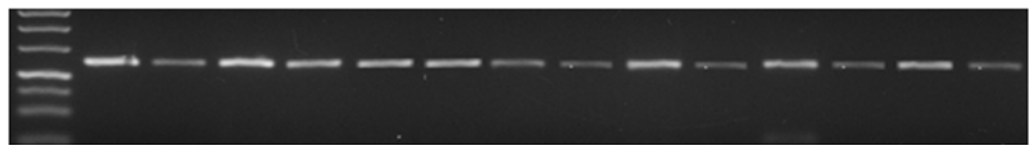

\section{SDCBP}

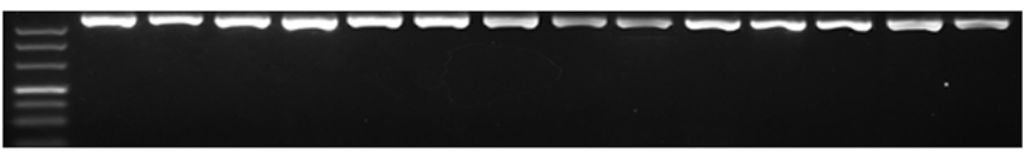

GAPDH

B

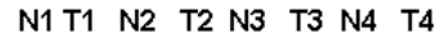

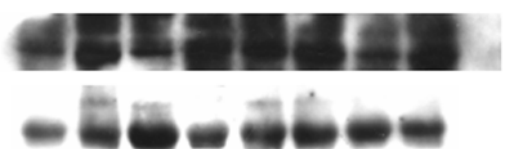

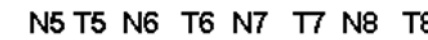
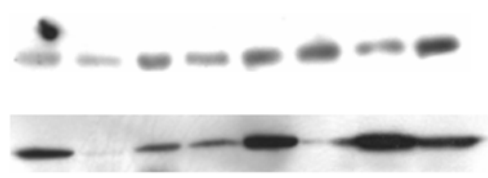

$=-m-\infty-$

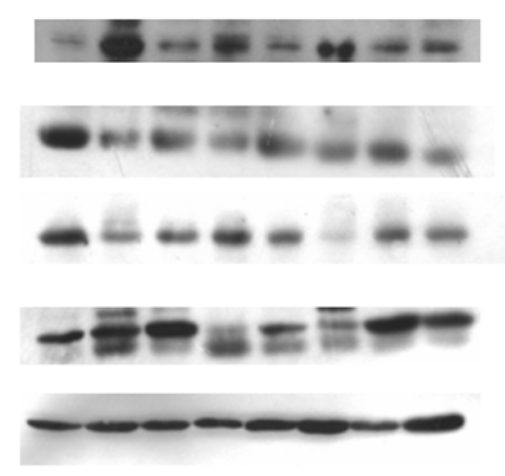

MID1-34kD

MID1-75kD

DKK1

MAP4K4

$\begin{array}{lllllll}\text { N1 } & \text { T1 N2 } & \text { T2 N3 } & \text { T3 N4 } & \text { T4 }\end{array}$
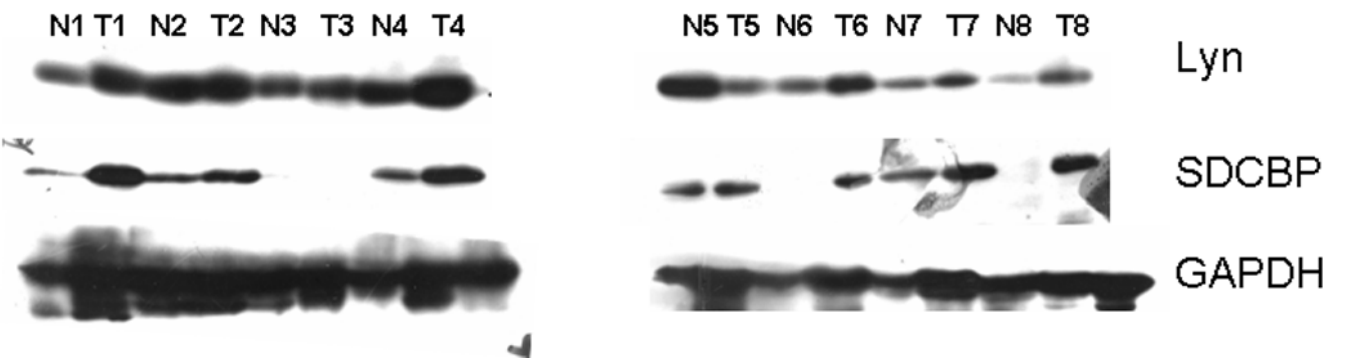

Figure 5. Expression of LYN, SDCBP, MAP4K4, DKKI, and MIDI in tumours. (A) Expression of the genes at the mRNA level detected by RT-PCR. (B) Expression of the genes at the protein level detected by western blotting. Paired tissues from different patients: $N$, normal tissue; $T$, colorectal tumour tissue

Of the 32 candidate genes, some have been well studied in CRC or metastasis, while others are poorly understood in CRC or metastasis. It has been noted that CA2 [17], CD24 [18,19], DKK1 [20], DSC2 [21], HOXB8 [22], LYN [23], SEMA3A [24], THBS1 [25], and VDR [26] are related with CRC; ARNTL, DKK1, DSC2, LYN, UPP1, and VDR are involved in the regulation of adhesion, growth, sensitivity or resistance to anti-cancer drugs of CRC. In addition, COL6A3 [27], EVI1 [28], and MARCKS [29] are known to be associated with the progression of breast cancer, melanoma or prostate cancer. We selected LYN, SDCBP, MAP4K4, DKK1, and MID1 for profound investigations because their roles in CRC metastasis are unclear. However, it is known that DKK1 is involved in embryonic development by inhibition 
A
MAP4K4
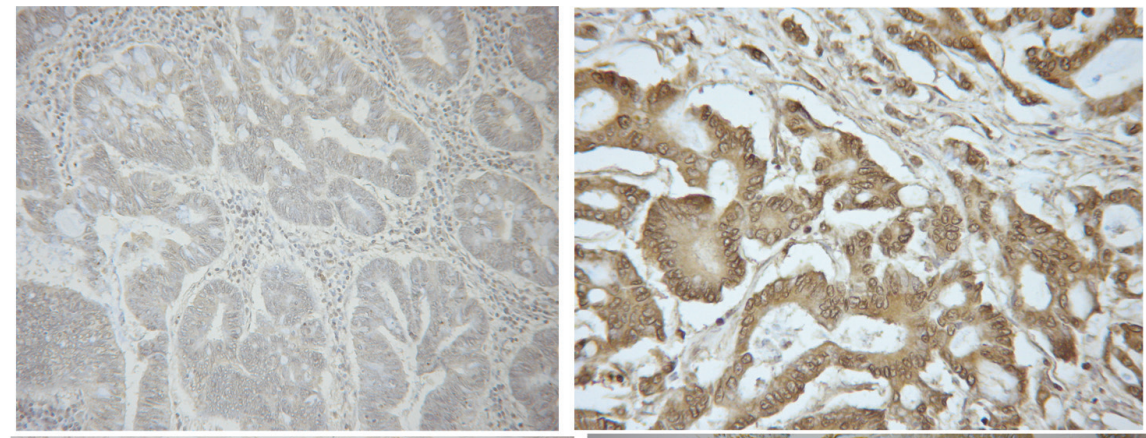

B

LYN
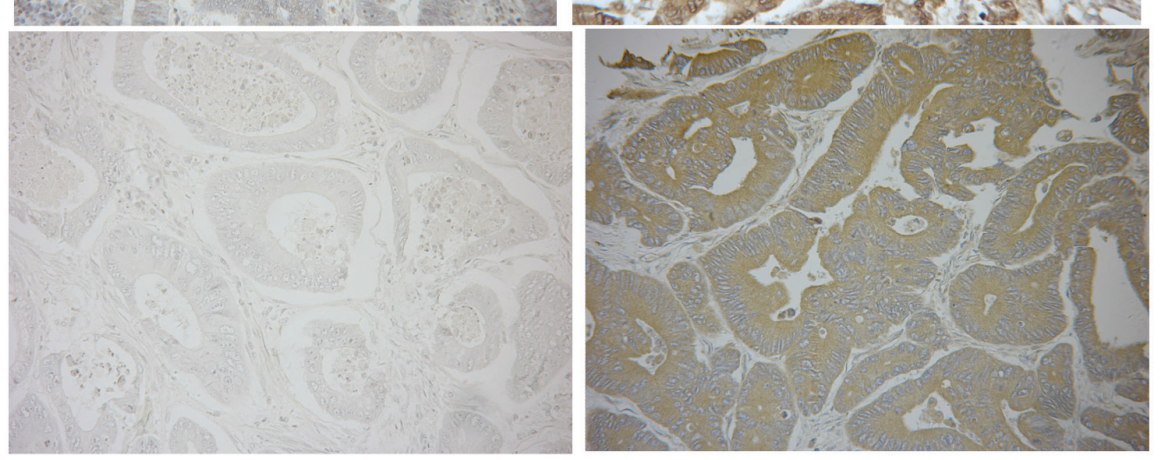

C
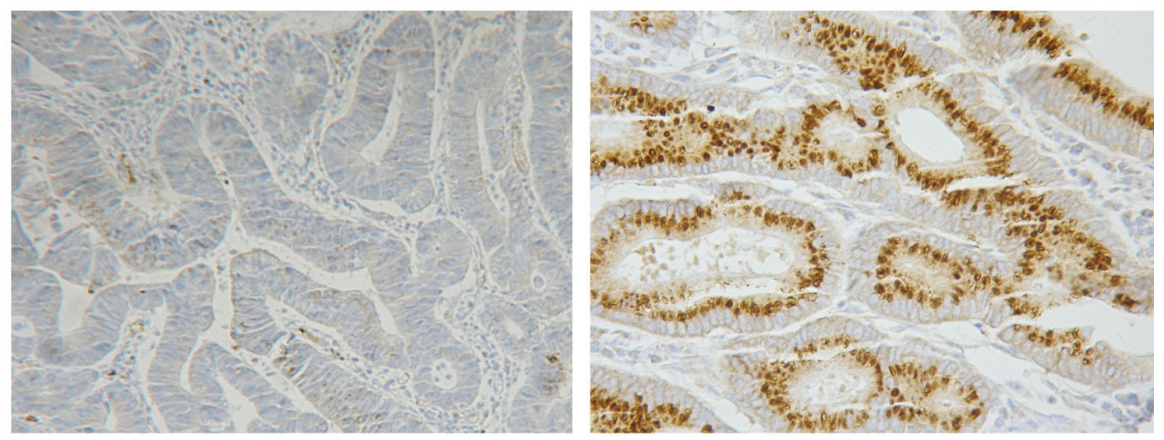

D

SDCBP
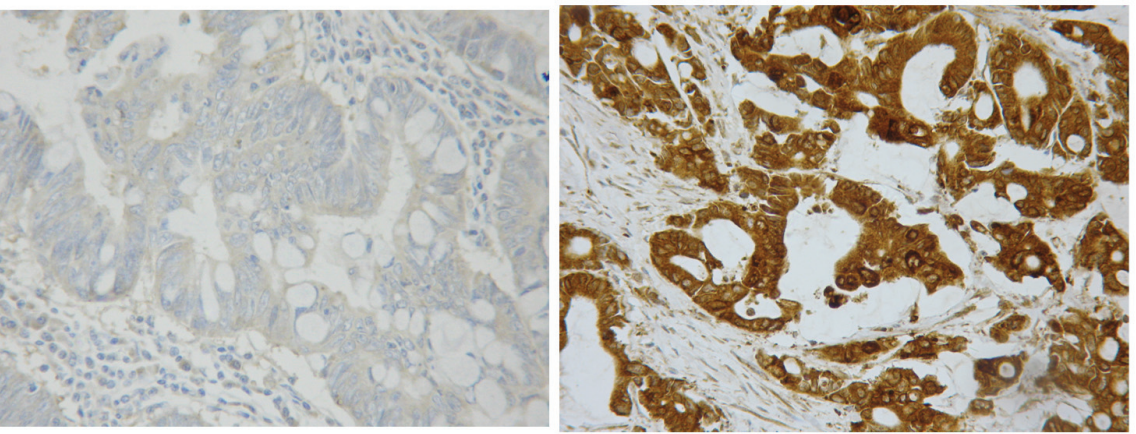

E

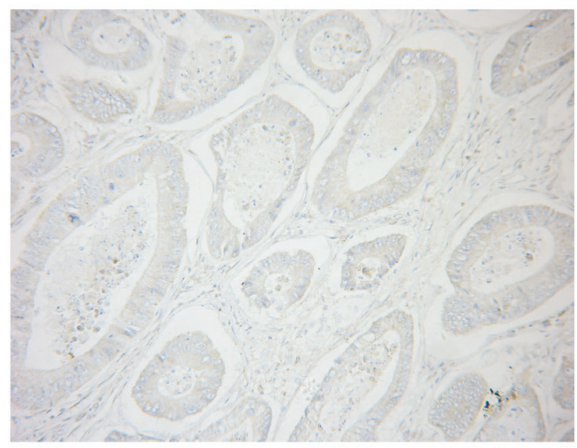

Low expression

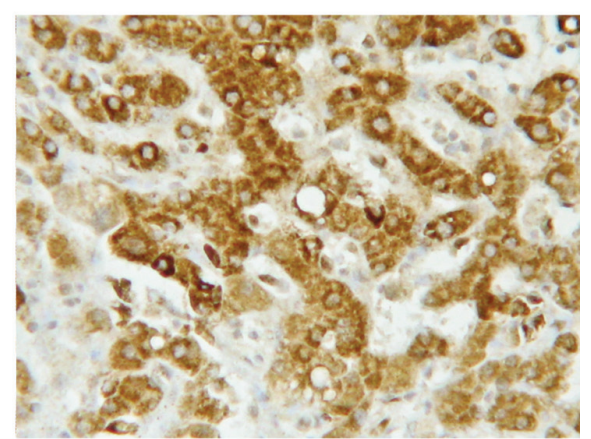

High expression

Figure 6. Immunohistochemical analysis of MAP4K4, LYN, SDCBP, DKKI, and MIDI on colorectal tumours. Low expression in some tumour tissues is presented in the panels on the left and high expression in tumour tissues in the panels on the right. Original magnification: $400 x$ 

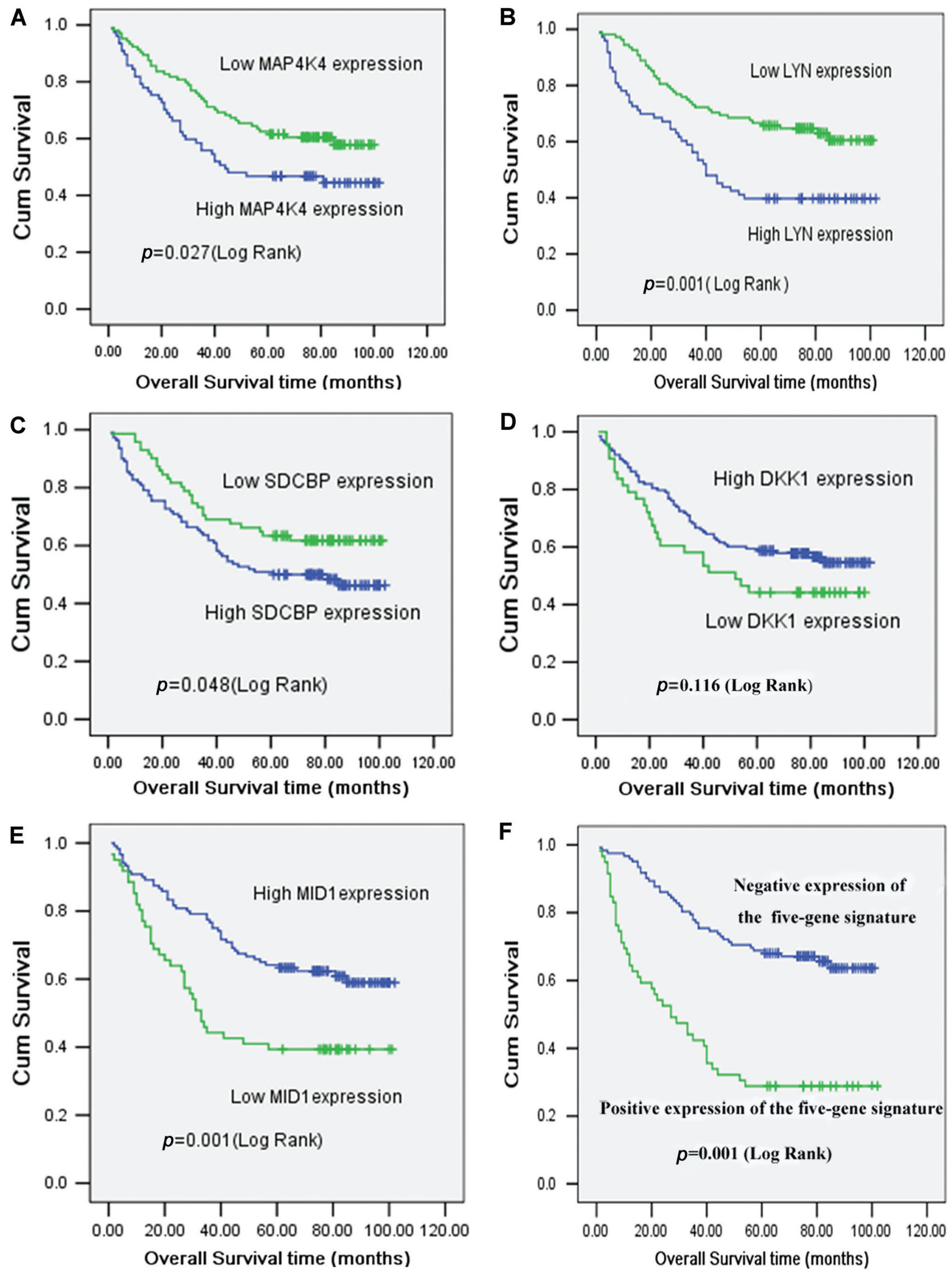

Figure 7. Correlations of the expression of LYN, SDCBP, MAP4K4, DKKI, MIDI, and the five-gene signature with Kaplan-Meier overall survival of CRC patients. The log-rank test was used to calculate $p$ values 
of the WNT signalling pathway [30]; DKK1 has been studied in colon [30,31] and gastric cancers [32]. LYN is a Src family protein tyrosine kinase expressed preferentially in haematopoietic cells and B cells. It was shown that activation of LYN stimulated cell proliferation and inhibited apoptosis. The expression of LYN has also been reported in solid tumours including prostate cancer [33], pancreatic cancer [34], colon carcinoma [35], and Kaposi's sarcoma [36]. LYN induced chemoresistance in colon cancer cell lines via the PI3-K/PKB-mediated cell survival pathway [35]. MID1 is a member of the tripartite motif (TRIM) family. It is involved in the formation of multi-protein structures, acting as anchor points to microtubules [37]. SDCBP (also called mda-9, syntenin) contains tandemly repeated PDZ domains that bind the cytoplasmic $\mathrm{C}$-terminal domains of a variety of transmembrane proteins, which affect cytoskeletalmembrane organization, cell adhesion, protein trafficking, and activation of transcription factors. SDCBP was up-regulated in metastatic melanomas $[38,39]$ and breast and gastric carcinomas [40]. Recently, SDCBP was shown to be an essential gene in the control of melanoma progression and metastasis [39]. MAP4K4 is a member of the serine/threonine protein kinase family. It is known that MAP4K4 specifically activates MAPK8/JNK [41] and is involved in cell migration and invasion in ovarian cancer [42] and breast cancer [43].

In this study, we found that LYN and SDCBP were up-regulated, while DKK1 and MID1 were downregulated in colorectal tumours. The expression of LYN, MAP4K4, and the five-gene signature were closely associated with metastasis and Dukes' stage of CRC. In addition, the expression of MAP4K4, LYN, SDCBP, MID1, and the five-gene signature correlated significantly with the overall survival of CRC patients. Moreover, the expression of MID1 and the five-gene signature were independent prognostic factors for CRC patients, of which the five-gene signature was the best prognostic factor. Our findings provided new insights into the role of these genes, particularly the five-gene signature in CRC progression.

As the genes of interest function in various molecular pathways, their promotion of CRC metastasis would be achieved by means of regulating numerous signalling pathways. However, the fact that the fivegene signature correlates more closely with the metastasis and overall survival of CRC patients suggests that the concerted effects of many genes, the regulation of several pathways, and the cross-interactions of the pathways would be more important in CRC metastasis and patient survival. It has been reported that the combination of some genes in the metastasis signature led to a more aggressive metastatic activity of the breast cancer cell population [10]. Clearly, how the five-gene signature regulates the metastasis of CRC needs to be further investigated. siRNA-mediated knockdown in highly metastatic CRC cell lines and virus-mediated knock-in in poorly metastatic CRC cell lines of individual genes and the gene combination will be our future work. Further investigations with additional patient cohorts and delineation of the specific roles of these genes in the metastatic process may lead to a better understanding of the metastatic mechanisms and the development of a novel therapeutic strategy.

\section{Acknowledgements}

We would like to thank Dinah Gorelik for critical reading of the manuscript. This work was funded by the National Nature Science Foundation of China (grant Nos 30670968, 30670967, and 30971361). This work was also supported by Fostering Funds for Distinguished Young Scientists of Southern Medical University and Municipal Programs of Guangzhou for Science and Technology Development (No.2007Z3-E4011).

\section{References}

Note: Reference 44 is cited in the Supporting information to this article.

1. Swanton C, Caldas C. Molecular classification of solid tumours: towards pathway-driven therapeutics. $\mathrm{Br} J$ Cancer 2009;100:1517-1522.

2. Acharya CR, Hsu DS, Anders CK, Anguiano A, Salter KH, Walters KS, et al. Gene expression signatures, clinicopathological features, and individualized therapy in breast cancer. $J$ Am Med Assoc 2008;299:1574-1587.

3. Garcia-Escudero R, Paramio JM. Gene expression profiling as a tool for basic analysis and clinical application of human cancer. Mol Carcinog 2008;47:573-579.

4. van't Veer LJ, Dai H, van de Vijver MJ, He YD, Hart AA, Mao M, et al. Gene expression profiling predicts clinical outcome of breast cancer. Nature 2002;415:530-536.

5. Glinsky GV, Glinskii AB, Stephenson AJ, Hoffman RM, Gerald WL. Gene expression profiling predicts clinical outcome of prostate cancer. J Clin Invest 2004;113:913-923.

6. Ramaswamy S, Ross KN, Lander ES, Golub TR. A molecular signature of metastasis in primary solid tumors. Nature Genet 2003;33:49-54.

7. van de Vijver MJ, He YD, van't Veer LJ, Dai H, Hart AA, Voskuil DW, et al. A gene-expression signature as a predictor of survival in breast cancer. N Engl J Med 2002;347:1999-2009.

8. Kallioniemi A. Molecular signatures of breast cancer - predicting the future. N Engl J Med 2002;347:2067-2068.

9. Kang Y, Siegel PM, Shu W, Drobnjak M, Kakonen SM, CordonCardo $\mathrm{C}$, et al. A multigenic program mediating breast cancer metastasis to bone. Cancer Cell 2003;3:537-549.

10. Minn AJ, Gupta GP, Siegel PM, Bos PD, Shu W, Giri DD, et al. Genes that mediate breast cancer metastasis to lung. Nature 2005;436:518-524.

11. Bos PD, Zhang XH, Nadal C, Shu W, Gomis RR, Nguyen DX, et al. Genes that mediate breast cancer metastasis to the brain. Nature 2009;459:1005-1009.

12. Wang S, Zhou J, Wang XY, Hao JM, Chen JZ, Zhang XM, et al. Down-regulated expression of SATB2 is associated with metastasis and poor prognosis in colorectal cancer. J Pathol 2009;219:114-122.

13. Huang ZX, Tian HY, Hu ZF, Zhou YB, Zhao J, Yao KT. GenCLiP: a software program for clustering gene lists by literature profiling and constructing gene co-occurrence networks related to custom. BMC Bioinformatics 2008;9:308.

14. Masunaga R, Kohno H, Dhar DK, Ohno S, Shibakita M, Kinugasa $\mathrm{S}$, et al. Cyclooxygenase-2 expression correlates with tumor neovascularization and prognosis in human colorectal carcinoma patients. Clin Cancer Res 2000;6:4064-4068.

15. Soumaoro LT, Uetake H, Higuchi T, Takagi Y, Enomoto M, Sugihara K. Cyclooxygenase-2 expression: a significant prognostic 
indicator for patients with colorectal cancer. Clin Cancer Res 2004;10:8465-8471.

16. Winter J, Lehmann T, Krauss S, Trockenbacher A, Kijas Z, Foerster J, et al. Regulation of the MID1 protein function is finetuned by a complex pattern of alternative splicing. Hum Genet 2004; 114:541-552.

17. Ki DH, Jeung HC, Park CH, Kang SH, Lee GY, Lee WS, et al. Whole genome analysis for liver metastasis gene signatures in colorectal cancer. Int J Cancer 2007;121:2005-2012.

18. Sagiv E, Memeo L, Karin A, Kazanov D, Jacob-Hirsch J, Mansukhani M, et al. CD24 is a new oncogene, early at the multistep process of colorectal cancer carcinogenesis. Gastroenterology 2006;131:630-639.

19. Sagiv E, Starr A, Rozovski U, Khosravi R, Altevogt P, Wang T, et al. Targeting CD24 for treatment of colorectal and pancreatic cancer by monoclonal antibodies or small interfering RNA. Cancer Res 2008;68:2803-2812.

20. Aguilera O, Pena C, Garcia JM, Larriba MJ, Ordonez-Moran P, Navarro D, et al. The Wnt antagonist DICKKOPF-1 gene is induced by 1alpha,25-dihydroxyvitamin D3 associated to the differentiation of human colon cancer cells. Carcinogenesis 2007;28: $1877-1884$

21. Khan K, Hardy R, Haq A, Ogunbiyi O, Morton D, Chidgey M. Desmocollin switching in colorectal cancer. $\mathrm{Br} J$ Cancer 2006;95: $1367-1370$

22. Vider BZ, Zimber A, Hirsch D, Estlein D, Chastre E, Prevot S, et al. Human colorectal carcinogenesis is associated with deregulation of homeobox gene expression. Biochem Biophys Res Commun 1997;232:742-748.

23. Chen WS, Kung HJ, Yang WK, Lin W. Comparative tyrosinekinase profiles in colorectal cancers: enhanced arg expression in carcinoma as compared with adenoma and normal mucosa. Int J Cancer 1999;83:579-584.

24. Nguyen QD, Rodrigues S, Rodrigue CM, Rivat C, Grijelmo C, Bruyneel E, et al. Inhibition of vascular endothelial growth factor (VEGF)-165 and semaphorin 3A-mediated cellular invasion and tumor growth by the VEGF signaling inhibitor ZD4190 in human colon cancer cells and xenografts. Mol Cancer Ther 2006;5:2070-2077.

25. Rashid A, Shen L, Morris JS, Issa JP, Hamilton SR. CpG island methylation in colorectal adenomas. Am J Pathol 2001;159:1129-1135.

26. Evans SR, Nolla J, Hanfelt J, Shabahang M, Nauta RJ, Shchepotin IB. Vitamin D receptor expression as a predictive marker of biological behavior in human colorectal cancer. Clin Cancer Res 1998;4:1591-1595.

27. Tilman G, Mattiussi M, Brasseur F, van Baren N, Decottignies A. Human periostin gene expression in normal tissues, tumors and melanoma: evidence for periostin production by both stromal and melanoma cells. Mol Cancer 2007;6:80.

28. Brooks DJ, Woodward S, Thompson FH, Dos Santos B, Russell M, Yang JM, et al. Expression of the zinc finger gene EVI-1 in ovarian and other cancers. Br J Cancer 1996;74:1518-1525.

29. Li T, Li D, Sha J, Sun P, Huang Y. MicroRNA-21 directly targets MARCKS and promotes apoptosis resistance and invasion in prostate cancer cells. Biochem Biophys Res Commun 2009;383:280-285.

30. Gonzalez-Sancho JM, Aguilera O, Garcia JM, Pendas-Franco N, Pena C, Cal S, et al. The Wnt antagonist DICKKOPF-1 gene is a downstream target of beta-catenin/TCF and is downregulated in human colon cancer. Oncogene 2005;24:1098-1103.

31. Aguilera O, Fraga MF, Ballestar E, Paz MF, Herranz M, Espada J, et al. Epigenetic inactivation of the Wnt antagonist DICKKOPF1 (DKK-1) gene in human colorectal cancer. Oncogene 2006;25:4116-4121.

32. Sato H, Suzuki H, Toyota M, Nojima M, Maruyama R, Sasaki S, et al. Frequent epigenetic inactivation of DICKKOPF family genes in human gastrointestinal tumors. Carcinogenesis 2007;28:2459-2466.

33. Goldenberg-Furmanov M, Stein I, Pikarsky E, Rubin H, Kasem S, Wygoda M, et al. Lyn is a target gene for prostate cancer: sequence-based inhibition induces regression of human tumor xenografts. Cancer Res 2004;64:1058-1066.

34. Fu Y, Zagozdzon R, Avraham R, Avraham HK. CHK negatively regulates Lyn kinase and suppresses pancreatic cancer cell invasion. Int J Oncol 2006;29:1453-1458.

35. Bates RC, Edwards NS, Burns GF, Fisher DE. A CD44 survival pathway triggers chemoresistance via lyn kinase and phosphoinositide 3-kinase/Akt in colon carcinoma cells. Cancer Res 2001;61:5275-5283.

36. Munshi N, Ganju RK, Avraham S, Mesri EA, Groopman JE. Kaposi's sarcoma-associated herpesvirus-encoded G proteincoupled receptor activation of c-jun amino-terminal kinase/stressactivated protein kinase and lyn kinase is mediated by related adhesion focal tyrosine kinase/proline-rich tyrosine kinase 2. J Biol Chem 1999;274:31863-31867.

37. Tao H, Simmons BN, Singireddy S, Jakkidi M, Short KM, Cox TC, et al. Structure of the MID1 tandem B-boxes reveals an interaction reminiscent of intermolecular ring heterodimers. Biochemistry 2008;47:2450-2457.

38. Helmke BM, Polychronidis M, Benner A, Thome M, Arribas J, Deichmann M. Melanoma metastasis is associated with enhanced expression of the syntenin gene. Oncol Rep 2004;12:221-228.

39. Boukerche H, Su ZZ, Prevot C, Sarkar D, Fisher PB. mda9/Syntenin promotes metastasis in human melanoma cells by activating c-Src. Proc Natl Acad Sci U S A 2008;105:15914-15919.

40. Koo TH, Lee JJ, Kim EM, Kim KW, Kim HD, Lee JH. Syntenin is overexpressed and promotes cell migration in metastatic human breast and gastric cancer cell lines. Oncogene 2002;21:4080-4088.

41. Collins CS, Hong J, Sapinoso L, Zhou Y, Liu Z, Micklash K, et al. A small interfering RNA screen for modulators of tumor cell motility identifies MAP4K4 as a promigratory kinase. Proc Natl Acad Sci U S A 2006;103:3775-3780.

42. Urzua U, Roby KF, Gangi LM, Cherry JM, Powell JI, Munroe DJ. Transcriptomic analysis of an in vitro murine model of ovarian carcinoma: functional similarity to the human disease and identification of prospective tumoral markers and targets. J Cell Physiol 2006;206:594-602.

43. Wang T, Lee K, Rehman A, Daoud SS. PRIMA-1 induces apoptosis by inhibiting JNK signaling but promoting the activation of Bax. Biochem Biophys Res Commun 2007;352:203-212.

44. Rashidi B, Gamagami R, Sasson A, Sun FX, Geller J, Moossa AR, et al. An orthotopic mouse model of remetastasis of human colon cancer liver metastasis. Clin Cancer Res 2000;6:2556-2561. 


\section{SUPPORTING INFORMATION ON THE INTERNET}

The following supporting information may be found in the online version of this article.

\section{Supplemental experimental procedures.}

Table S1. Tumour growth under subcutaneous tissue of nude mice of SCPs including SCP3, SCP9, SCP10, SCP20, SCP28, SCP51, SCP58, and SW480/EGFP (mean \pm SD, $n=3$ ).

Table S2. Cell cycles of SCP51, SCP58, and their parent SW480/EGFP cells detected by flow cytometry (mean $\pm \mathrm{SD}, n=3$ ).

Table S3. The differential genes between SCP51 and SCP58 cells (SCP51 versus SCP58).

Table S4. The differential genes between SW480/EGFP and SCP58 (SW480/EGFP versus SCP58).

Table S5. Common genes found as the candidates for CRC metastasis when cross-comparing differential genes expressed between SCP51 and SCP58 cells with the differential genes found between SCP58 and SW480/EGFP.

Table S6. Genes found in the top ten clusters using gene-annotation enrichment analysis of DAVID.

Table S7. Fold changes in the genes of the top ten clusters using gene-annotation enrichment analysis of DAVID in SCP51, SCP58 and SW480/EGFP cells.

Table S8. A 32-gene set associated with metastasis of CRC using cross-comparing, functional analysis and gene annotation, text mining. 